\title{
Evaluation of Acute In-stent Thrombosis during Stent-assisted Coil Embolization of Unruptured Intracranial Aneurysms
}

\author{
Kouhei NiI, ${ }^{1}$ Ritsurou InOUE, ${ }^{1}$ Yusuke MORINAGA, ${ }^{1}$ \\ Takafumi MITSUTAKE, ${ }^{1}$ and Hayatsura HANADA ${ }^{1}$ \\ ${ }^{1}$ Department of Neurosurgery, Fukuoka University Chikushi Hospital, \\ Chikushino, Fukuoka, Japan
}

\begin{abstract}
Stent-assisted coil embolization (SACE) is used to address wide-necked or complex aneurysms. However, periprocedural and/or late in-stent thrombosis (IST) elicit neurological events. We investigated the incidence and timed the development of acute IST during SACE with braided- or laser-cut stents in a retrospective study. Between May 2013 and April 2018, we evaluated 11 ISTs that occurred in the course of 185 SACE procedures (self-expandable laser-cut stent, $n=128$; braided stent, $n=57$ ). The onset of IST was measured from the time of stent placement. All 11 patients with IST were treated with anticoagulants and underwent hypertension induction. Post-procedural neurological events due to IST were also recorded. The implantation of a laser-cut stent elicited IST in 5 of 128 patients (3.9\%); braided stent placements resulted in IST in 6 of 57 patients $(10.5 \%)(P=0.1)$. The mean stent diameter was significantly smaller in patients with-IST than without IST $(3.0 \pm 0.9 \mathrm{~mm}$ vs. $4.5 \pm 0.7 \mathrm{~mm}, P=0.007)$. The mean interval between stent placement and IST onset was $19 \pm 7.7 \mathrm{~min}$; it was significantly earlier for braidedthan laser-cut stents $(17.5 \pm 4.1 \mathrm{~min}$ vs. $29.0 \pm 4.8 \mathrm{~min}, P=\mathbf{0 . 0 0 6})$. All ISTs were resolved during the procedure. Three patients experienced postoperative neurologic events. We recommend the meticulous and prolonged monitoring of images after stent placement because delayed intraoperative IST can occur especially when laser-cut stents are used.
\end{abstract}

Key words: in-stent thrombosis, intracranial aneurysm, stent-assisted coil embolization, complication

\section{Introduction}

Stent-assisted coil embolization (SACE) for intracranial aneurysms lowers the rate of coil protrusion into the parent artery and is particularly recommended to address wide-necked or complex aneurysms. ${ }^{1,2)}$ However, SACE is associated with a risk of in-stent thrombosis (IST) and ischemic complications. ${ }^{3-9)}$ Despite the routine use of antiplatelet therapy and heparinization in conjunction with SACE, a certain incidence of IST is to be expected. Therefore, its early identification is important to prevent neurologic complications. In a retrospective study, we investigated the incidence and timed the development of acute IST during SACE.

Received May 15, 2018; Accepted July 17, 2018

Copyright $\subset 2018$ by The Japan Neurosurgical Society This work is licensed under a Creative Commons AttributionNonCommercial-NoDerivatives International License.

\section{Materials and Methods}

We retrospectively evaluated clinical and radiological data of 185 patients with unruptured intracranial aneurysms (84 men and 101 women; mean age $66.0 \pm 12.6$ years) underwent SACE procedures between May 2013 and April 2018 at our institute. The ethics committee of our institution approved this study and informed consent was obtained from all patients or their legal representatives after full explanation of the procedures. For at least 7 days before SACE, all patients underwent dual- or triple antiplatelet therapy selected depending on the result of aspirin- and P2Y12 reaction units. Dual antiplatelet therapy consisted of aspirin (100 mg daily) and clopidogrel (75 mg daily) or cilostazol (200 mg daily). Triple antiplatelet therapy was selected in cases of aspirin or clopidogrel non-responders or the absence of assay; it consisted of aspirin (100 $\mathrm{mg}$ daily), clopidogrel (75 mg daily), and cilostazol (100 mg daily). ${ }^{10)}$ 
All SACEs were performed under general anesthesia and systemic heparinization. We placed 128 laser-cut stents [28 Enterprise VRD stents (Codman, Raynham, MA, USA), 100 Neuroform stents (Stryker, Fremont, CA, USA)], and 57 braided stents [LVIS stents (MicroVention TERUMO, Tustin, CA, USA)]. Stent selection was based on the status of the parent arteries and aneurysms. We favored the 'jailing' technique in which the stent is deployed after introducing a microcatheter into the aneurysm. In all cases, the intravenous (iv) injection of ozagrel sodium (40 mg) was started immediately after stent placement.

Intraoperative angiography was performed at 5-min intervals. When shadow defects were observed at the level of stent placement on intraprocedural angiograms, IST was recorded. Of the 185 patients, $11(5.9 \%)$ developed acute intraoperative IST; its onset was measured from the time of stent placement. All ISTs were treated by anticoagulant therapy (additional systemic heparinization and/or $20 \mathrm{mg}$ argatroban) and induced hypertension [norepinephrine or dopamine delivered iv to maintain a systolic blood pressure $(\mathrm{SBP})>120 \mathrm{mmHg}$. The time to IST abatement was recorded and treatments were continued until it was angiographically confirmed on the first postoperative day. IST-related neurologic events were categorized as transient ischemic attacks (TIAs, neurologic deficits lasting $<24 \mathrm{~h}$ ), minor stroke [neurologic deficits lasting $>24 \mathrm{~h}$ with a National Institutes of Health Stroke Scale score (NIHSS) < 4], and major stroke (neurologic deficit lasting $>24 \mathrm{~h}$, NIHSS $>4$ ).

The characteristics, angiographic results, and clinical outcomes were evaluated in all 11 patients with acute IST. The IST was analyzed using multiple logistic regression analysis; the covariates were the age, sex, antiplatelet agent type, stent type, and stent size. A stepwise method was applied for the selection of variables. Continuous variables were expressed as the mean \pm one standard deviation (SD), categorical variables in terms of percentages. The Fisher exact test was used for categoric- and the Mann-Whitney $U$-test for continuous variables. Differences of $P<$ 0.05 were considered statistically significant.

\section{Results}

Table 1 shows the relationship between the patient characteristics and acute IST development. IST occurred after five laser-cut- and six braided stent placements. The patient age, sex, pre-procedural antiplatelet agent type, and the stent type were not significantly different in patients with- and without IST.
Table 1 Comparison of the characteristics of 185 patients with/without acute in-stent thrombosis

\begin{tabular}{lccc}
\hline & IST $(n=11)$ & $\begin{array}{c}\text { Non-IST } \\
(n=174)\end{array}$ & $P$-value \\
\hline Age (mean \pm SD, y) & $60.0 \pm 14.3$ & $66.0 \pm 12.5$ & $0.06^{*}$ \\
Male, $n(\%)$ & $5(45.5)$ & $79(45.4)$ & $>0.5^{+}$ \\
$\begin{array}{l}\text { Triple antiplatelet } \\
\text { therapy, } n \text { (\%) }\end{array}$ & $5(45.5)$ & $104(59.8)$ & $0.4^{+}$ \\
$\begin{array}{l}\text { Stent type } \\
\text { Laser-cut, } n(\%)\end{array}$ & $5(45.5)$ & $123(70.7)$ & $0.1^{+}$ \\
$\quad$ Braided, $n(\%)$ & $6(54.5)$ & $51(29.3)$ & $0.1^{+}$ \\
$\begin{array}{l}\text { Stent size } \\
\quad \text { Diameter } \\
\text { (mean } \pm \text { SD, mm) }\end{array}$ & $3.0 \pm 0.9$ & $4.5 \pm 0.7$ & $0.007^{*}$ \\
$\begin{array}{l}\text { Length } \\
\text { (mean } \pm \text { SD, mm) }\end{array}$ & $21.0 \pm 4.5$ & $21.0 \pm 4.1$ & $0.4^{*}$ \\
$\begin{array}{l}\text { Neurologic event, } \\
n \text { (\%) }\end{array}$ & $3(27.3)$ & $15(8.6)$ & $0.08^{+}$ \\
$\begin{array}{l}\text { TIA, } n(\%) \\
\text { Minor, } n \text { (\%) }\end{array}$ & $1(9.1)$ & $5(2.9)$ & $0.3^{+}$ \\
Major, $n(\%)$ & $2(18.2)$ & $8(4.6)$ & $0.1^{+}$ \\
\hline
\end{tabular}

IST: acute in-stent thrombosis, Major: major stroke (NIHSS > 4), Minor: minor stroke (NIHSS < 4), n: number of procedures, SD: standard deviation, TIA: transient ischemic attack, ${ }^{\dagger}$ by the Fisher exact test, *by the Mann-Whitney $U$-test.

The overall mean stent diameter and length were and $4.5 \pm 0.7$ and $21.0 \pm 4.1 \mathrm{~mm}$, respectively. The mean stent diameter was significantly smaller in patients with- than without IST group $(3.0 \pm 0.9 \mathrm{~mm}$ vs. $4.5 \pm 0.7 \mathrm{~mm}, P=0.007)$; the mean stent length was not significantly different $(P>0.5)$. A smaller stent diameter was significant in the development of IST (odds ratio 5.35, 95\% confidence interval 1.39-20.64, $P=0.015$ ).

Neurologic events occurred after 18 of the 185 procedures (9.7\%); six patients $(3.2 \%)$ developed TIA, $10(5.4 \%)$ a minor- and two $(1.1 \%)$ a major stroke. Acute IST resulted in a higher incidence of neurologic event $(27.3 \%$ vs. $8.6 \%, P=0.08)$.

Table 2 shows the characteristics of the 11 patients (five men, $45.5 \%$; six women $54.5 \%$ ) who developed acute IST; their mean age was $53.0 \pm 12.8$ years. Of the ISTs, five were on the internal carotid artery, two on the middle cerebral artery (MCA), two on the anterior communicating artery (AcomA). Of the remaining two, one of each was on the basilar artery or the posterior cerebral artery. The mean aneurysmal dome and neck size of the 11 aneurysms was $8.4 \pm 3.3 \mathrm{~mm}$ and $4.9 \pm 1.6 \mathrm{~mm}$, respectively.

Acute IST developed after the placement of $1 / 28$ (3.1\%) Enterprise VRD-, 4/100 (4.0\%) Neuroform-, 
Table 2 Patient characteristics, stent devices, and clinical outcomes in 11 patients with acute in-stent thrombosis during stent-assisted coil embolization

\begin{tabular}{|c|c|c|c|c|c|c|c|}
\hline \multirow{2}{*}{$\begin{array}{l}\text { Patient } \\
\text { no. }\end{array}$} & \multicolumn{2}{|c|}{ Aneurysm } & \multicolumn{2}{|c|}{ Self-expandable stent } & \multicolumn{2}{|c|}{ Time of IST (min) } & \multirow{2}{*}{$\begin{array}{c}\text { Neurologic } \\
\text { event }\end{array}$} \\
\hline & Location & $\begin{array}{c}\text { Dome/neck } \\
(\mathrm{mm})\end{array}$ & Type & $\begin{array}{l}\text { Size (diameter/ } \\
\text { length, mm) }\end{array}$ & Onset & Abatement & \\
\hline 1 & ICA & $9.3 / 5.0$ & Neuroform & $4.5 / 30$ & 25 & 45 & $(-)$ \\
\hline 2 & ICA & $14.7 / 5.8$ & Neuroform & $4.5 / 20$ & 35 & 54 & $(-)$ \\
\hline 4 & ICA & $8.4 / 3.4$ & LVIS junior & $2.5 / 17$ & 9 & 51 & $(-)$ \\
\hline 5 & ICA & $11.4 / 5.9$ & Neuroform & $4.5 / 30$ & 29 & 36 & $(-)$ \\
\hline 6 & AcomA & $6.2 / 3.0$ & LVIS junior & $3.5 / 18$ & 19 & 54 & $(-)$ \\
\hline 7 & $\mathrm{BA}$ & $5.4 / 4.9$ & LVIS junior & $2.5 / 17$ & 19 & 38 & $(-)$ \\
\hline 11 & MCA & $7.7 / 3.3$ & Neuroform & $3.0 / 21$ & 21 & 18 & TIA \\
\hline
\end{tabular}

AcomA: anterior communicating artery, BA: basilar artery, ICA: internal carotid artery, IST: acute in-stent thrombosis, Major: major stroke (NIHSS > 4), MCA: middle cerebral artery, Minor: minor stroke (NIHSS < 4), n: number of procedures, PCA: posterior cerebral artery, SD: standard deviation, TIA: transient ischemic attack, VA: vertebral artery.

and 6/57 (10.5\%) LVIS stents; the difference was not statistically significant $(P=0.21)$. The mean IST onset time after stent placement was $19.0 \pm 7.7 \mathrm{~min}$. All ISTs were resolved intraoperatively by the administration of anticoagulants and by induced hypertension; the mean time to IST abatement was $45.0 \pm 10.6 \mathrm{~min}$. Three patients with IST (27.3\%) suffered neurologic events; one presented with TIA, two had minor strokes, and no patient had a major stroke.

Table 3 shows the relationship between acute IST and the self-expanding stent type. The rate of acute ISTs was higher for braided- than laser-cut stents (6/57, $10.5 \%$ vs. $5 / 128,3.9 \%)$; the difference was not statistically significant $(P=0.1)$. The mean time to IST onset, determined by multivariate regression analysis, was significantly longer with laser-cut- than braided stents (laser-cut, $29.0 \pm 4.8 \mathrm{~min}$ vs. $17.5 \pm$ $4.1 \mathrm{~min} ; P=0.006$ ). The mean time to IST abatement was $45.0 \pm 13.1 \mathrm{~min}$ for laser-cut- and 46.0 $\pm 7.6 \mathrm{~min}$ for braided stents $(P>0.5)$. Neurologic events due to IST occurred in two of five patients $(40.0 \%)$ who received laser-cut- and in one of six $(16.7 \%)$ treated with a braided stent $(P=0.08)$.

\section{Illustrative Cases}

Case 8: A 51-year-old man had undergone coil embolization of a ruptured AcomA aneurysm 5 years earlier. He came to us for further evaluation and treatment
Table 3 Relationship between the stent type and the incidence of acute in-stent thrombosis, the time to IST, to IST abatement, and the incidence of neurologic events

\begin{tabular}{lccc}
\hline & \multicolumn{3}{c}{ Stent type } \\
\cline { 2 - 4 } & $\begin{array}{c}\text { Laser-cut } \\
(n=128)\end{array}$ & $\begin{array}{c}\text { Braided } \\
(n=57)\end{array}$ & $P$-value \\
\hline $\begin{array}{l}\text { Number of IST, } n(\%) \\
\text { Time of IST }\end{array}$ & $5(3.9 \%)$ & $6(10.5 \%)$ & $0.1^{+}$ \\
$\quad \begin{array}{l}\text { Onset } \\
\text { (mean } \pm \text { SD, min) }\end{array}$ & $29.0 \pm 4.8$ & $17.5 \pm 4.1$ & $0.006^{*}$ \\
$\begin{array}{l}\text { Abatement } \\
\text { (mean } \pm \text { SD, min) }\end{array}$ & $45.0 \pm 13.1$ & $46.0 \pm 7.6$ & $>0.5^{*}$ \\
$\begin{array}{l}\text { Neurologic event } \\
\text { due to IST, } n(\%)\end{array}$ & $2 / 5(40.0 \%)$ & $1 / 6(16.7 \%)$ & $0.08^{+}$ \\
\hline
\end{tabular}

IST: acute in-stent thrombosis, $n$ : number of procedures, SD: standard deviation, 'by the Fisher exact test, *by the MannWhitney U-test.

because magnetic resonance angiography findings were suggestive of aneurysmal regrowth. Angiography confirmed regrowth of the aneurysmal neck and coil compaction (Fig. 1A) and he underwent SACE after 14-day dual-antiplatelet therapy. Based on the size of the parent artery, a LVIS Junior stent (fully open diameter $=2.5 \mathrm{~mm}$, length $=23 \mathrm{~mm}$ ) was placed to cover the aneurysm neck and coils were inserted in the aneurysm using the jailing technique under systemic heparinization and Ozagrel sodium administration (Fig. 1B). Left ACA occlusion due to acute 
IST was observed 11 min after stent placement (Fig. 1C) and additional heparin and/or argatroban were administered; norepinephrine was also delivered to maintain his SBP at more than $120 \mathrm{mmHg}$. The left ACA occlusion recanalized after anticoagulant- and induced hypertension therapy, and his IST abated gradually in the course of $44 \mathrm{~min}$ (Fig. 1D). His postoperative course was good without neurological deficits, and follow-up angiograms revealed no recurrence of IST on the day after SACE.

Case 11: A 53-year-old man was hospitalized for further evaluation and treatment of an unruptured right MCA aneurysm (Fig. 2A). At his request, endovascular treatment was performed. Because coil protrusion was observed under balloon remodeling and after application of the double-microcatheter technique, we placed a Neuroform Atlas stent (fully open diameter $=3.0 \mathrm{~mm}$, length $=21 \mathrm{~mm}$ ) and then inserted coils into the aneurysm (Fig. 2B). The aneurysm was treated as a small neck remnant. Acute IST occurred $21 \mathrm{~min}$ after stent placement (Fig. 2C). Additional anticoagulant therapy was delivered, and hypertension was induced. The IST subsequently resolved gradually in the course of $18 \mathrm{~min}$ (Fig. 2D). Although he reported transient left upper extremity weakness after waking up from general anesthesia, there was neither recurrence of IST nor hemorrhagic complication, and he was discharged without neurologic events.

\section{Discussion}

Thromboembolism and hemorrhage are the most common complications of SACE for wide-necked intracranial aneurysms. The reported thrombosis rates during SACE vary from $2 \%$ to $20 \%{ }^{3,6-9,11-14)}$ In our study, the rate of acute IST was $5.9 \%$. In an
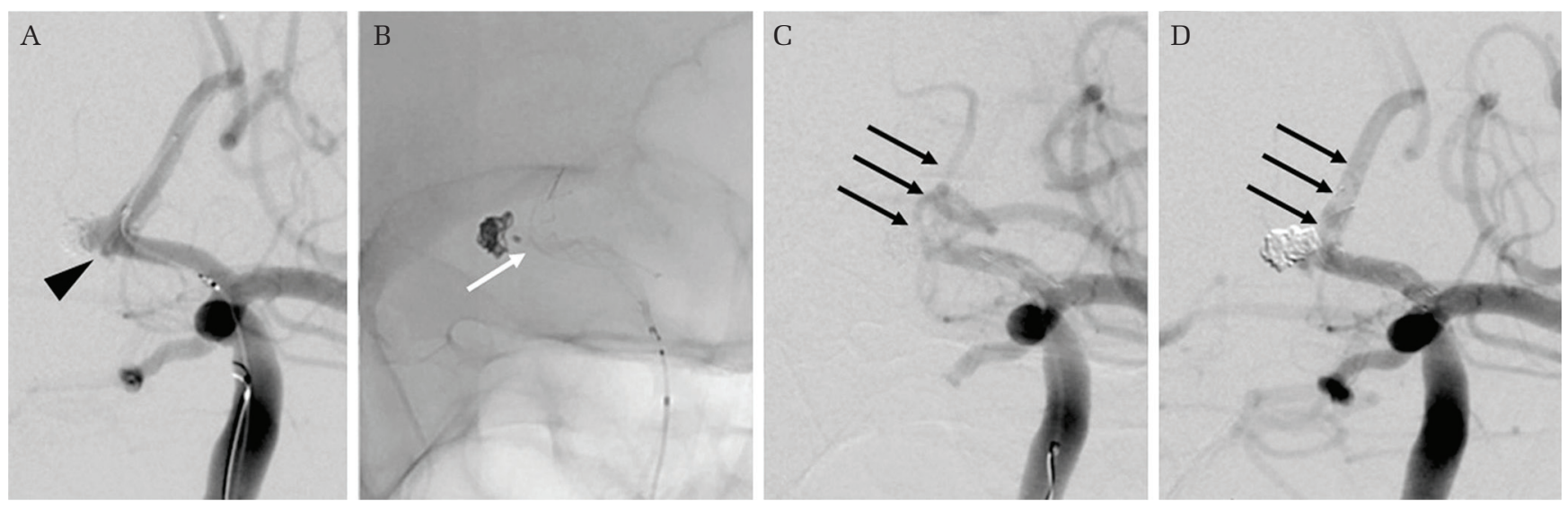

Fig. 1 Preoperative angiogram showing a recurrent anterior communicating artery aneurysm (A: arrowhead). A LVIS Junior stent was placed to cover the aneurysm neck after microcatheter insertion into the aneurysm (B: arrow). The intraoperative angiogram shows left anterior cerebral artery (ACA) occlusion due to acute in-stent thrombosis (IST) occurring $11 \mathrm{~min}$ after stent placement (C: arrows). The left ACA occlusion and IST gradually recanalized after anticoagulant therapy and induced hypertension (D: arrows).
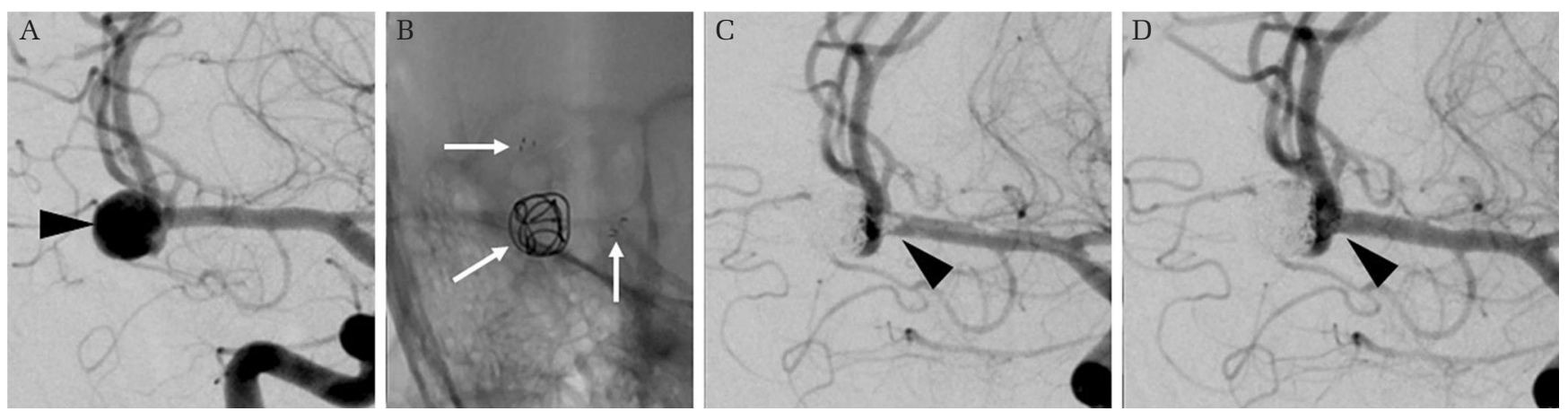

Fig. 2 Preoperative angiogram showing an unruptured right middle cerebral artery aneurysm (A: arrowhead). Coils were inserted into the aneurysm after placement of a Neuroform Atlas stent (B: arrows). Acute in-stent thrombosis occurred $44 \mathrm{~min}$ after stent placement (C: arrowhead). It resolved gradually $40 \mathrm{~min}$ after anticoagulant therapy and induced hypertension (D: arrowhead). 
earlier analysis of coronary disease, the placement of stents with a small diameter was an independent predictor of early and late IST. ${ }^{15)}$ Based on our experience, we recommend that patients implanted with small-diameter stents be carefully monitored to rule out the development of IST.

Surgeons modify antiplatelet and/or anticoagulant regimens because acute IST often elicits ischemic complications. However, as the premature or excessive prevention of IST may result in hemorrhagic complications before coil embolization, long-lasting or loading doses of dual-antiplatelet- and intraoperative anticoagulant therapy are commonly selected, and additional treatments for acute IST are delivered only after its occurrence. We encountered acute IST a mean of 19.0 min after stent deployment. Our findings show that patients must be monitored for tens of minutes after stent deployment to immediately detect the development of acute IST even when SACE is completed earlier than expected.

Interestingly, although there was no significant difference in the incidence of IST between the different stent types we deployed, it developed earlier after the placement of braided stents. Computational fluid dynamics modeling showed that wall shear stress was lower with LVIS than Enterprise stents because the LVIS stent provides denser metal coverage than the Enterprise device. ${ }^{16)}$ In fact, benchtop experiments revealed that LVIS stents yielded more average metal coverage than Enterprise and Neuroform stents (11.5-14\% vs. $5-10 \%) .{ }^{17)}$ This may explain why thrombus formation occurs earlier in braided than laser-cut stents.

Acute IST may be attributable to factors other than the stent design; different stenting procedures may also account for its occurrence. According to Cai et al., ${ }^{18)}$ the rate of thromboembolic complications is higher with coil-then-stent- than other procedures such as jailing or trans-cell methods. Although we applied the jailing-outside-the-stent technique in most of our cases, differences in the placement of the LVIS stent may have played a role. Unlike the Neuroform stent, the LVIS stent allows repositioning. Stent openness can be visually confirmed during LVIS stenting, this is not possible when Neuroform- or Enterprise stents are used. Consequently, in some cases, LVIS repositioning may result in iatrogenic intimal injury.

Meticulous intraoperative image observation is particularly important after the placement of lasercut stents. Early IST can be addressed immediately when attention is paid to angiograms obtained at the start of the procedure, during stent placement, and upon the insertion of framing coils. However, the number of angiograms performed tends to decrease during the insertion of filling- and finishing coils and SACE may be thought to be successful before IST is recognized. Thus, the detection and treatment of IST may be delayed in patients undergoing SACE with laser-cut stents.

Aspirin or clopidogrel resistance may affect the incidence of acute IST. Aspirin- and P2Y12 reaction units have been measured with the VerifyNow assay after the administration of antiplatelet agents. ${ }^{19,20)}$ The appropriate dose of other drugs must be determined before the procedure when the platelet reactivity units (PRUs) exceed an acceptable range. However, not all of our patients were subjected to this assay because it was introduced after the inception of our study. And triple antiplatelet therapy was selected in cases of aspirin or clopidogrel non-responders or the absence of VerifyNow assay. The PRUs vary in patients with coexisting diseases ${ }^{21)}$ and in the absence of consensus on the cut-off value for identifying aspirin or clopidogrel non-responders, data interpretation results in ambiguous findings. ${ }^{22}$ Nonetheless, a low PRU value is not necessarily predictive of an unsatisfactory treatment outcome. ${ }^{23)}$ Therefore, as we were unable to modify the antiplatelet dose before the procedures, we selected routine iv Ozagrel sodium administration. Ozagrel sodium, a thromboxane A2 synthase inhibitor, elicits an increase in prostacyclin and inhibits platelet aggregation; it has been used in patients with acute cerebral infarction ${ }^{24)}$ or thromboembolism during endovascular treatments in Japan. ${ }^{25)}$ We think that Ozagrel sodium administration may help to prevent acute IST due to different antiplatelet therapy.

Treatments for acute IST have been reported and the local intra-arterial and/or iv administration of glycoprotein IIb/IIIa inhibitors has been recommended. ${ }^{3,4,6-8,13,18)}$ As their use has not been approved in Japan, we use heparinization and argatroban for anticoagulant therapy. We induced hypertension when the effect of our anticoagulant regimen is thought to be insufficient. Although we could not deliver the yet unapproved antiplatelet- or anticoagulant therapy, all acute ISTs were resolved intraoperatively. However, the incidence of postoperative neurologic events in our patients with acute IST $(27.3 \%)$ was similar to earlier series (20-57\%).. ${ }^{3-9)}$ Our study also demonstrated that acute IST increased the risk for post-procedural neurologic events. The new antiplatelet or anticoagulant therapies with the early diagnosis may help to lower the incidence of acute IST and of related neurologic complications. Further studies must be required to determine whether new peri-procedural drug managements affect the development of acute or chronic IST in patients undergoing SACE. 


\section{Conclusion}

As the IST onset time differs for different stent types, the early detection of IST requires the acquisition and meticulous inspection of intraoperative images in patients undergoing SACE. Prompt treatment after the early diagnosis of acute IST may prevent the development of severe neurologic complications.

\section{Acknowledgment}

We are grateful to Masanori Tsutsumi, Kimiya Sakamoto, Fumihiro Hiraoka, and Ayumu Eto for their help with this study.

\section{Conflicts of Interest Disclosure}

The authors have no personal financial or institutional interest in any of the drugs, materials, or devices used in this study. All authors are members of The Japan Neurosurgical Society and all have registered self-reported COI Disclosure Statement Forms on-line.

\section{References}

1) Bendok BR, Parkinson RJ, Hage ZA, Adel JG, Gounis MJ: The effect of vascular reconstruction device-assisted coiling on packing density, effective neck coverage, and angiographic outcome: an in vitro study. Neurosurgery 61: 835-840; discussion $840-841,2007$

2) Henkes H, Bose A, Felber S, Miloslavski E, BergDammer E, Kühne D: Endovascular coil occlusion of intracranial aneurysms assisted by a novel selfexpandable nitinol microstent (neuroform). Interv Neuroradiol 8: 107-119, 2002

3) Amenta PS, Dalyai RT, Kung D, et al.: Stent-assisted coiling of wide-necked aneurysms in the setting of acute subarachnoid hemorrhage: experience in 65 patients. Neurosurgery 70: 1415-1429, 2012

4) Chalouhi N, Jabbour P, Kung D, Hasan D: Safety and efficacy of tirofiban in stent-assisted coil embolization of intracranial aneurysms. Neurosurgery 71: 710-714, 2012

5) Jankowitz B, Thomas AJ, Vora N, et al.: Risk of hemorrhage in combined neuroform stenting and coil embolization of acutely ruptured intracranial aneurysms. Interv Neuroradiol 14: 385-396, 2008

6) Maldonado IL, Machi P, Costalat V, Mura T, Bonafé A: Neuroform stent-assisted coiling of unruptured intracranial aneurysms: short- and midterm results from a single-center experience with 68 patients. AJNR Am J Neuroradiol 32: 131-136, 2011

7) Tähtinen OI, Vanninen RL, Manninen HI, et al.: Wide-necked intracranial aneurysms: treatment with stent-assisted coil embolization during acute $(<72$ hours) subarachnoid hemorrhage-experience in 61 consecutive patients. Radiology 253: 199-208, 2009

8) Vendrell JF, Costalat V, Brunel H, Riquelme C, Bonafe A: Stent-assisted coiling of complex middle cerebral artery aneurysms: initial and midterm results. AJNR Am J Neuroradiol 32: 259-263, 2011

9) Wang K, Sun Y, Li AM: Peri-procedural morbidity and mortality associated with stent-assisted coiling for intracranial aneurysms. Interv Neuroradiol 19: 43-48, 2013

10) Matsumoto $Y$, Iko $M$, Tsutsumi $M$, et al.: The safety and efficacy of triple antiplatelet therapy after intracranial stent-assisted coil embolization. J Stroke Cerebrovasc Dis 24: 1513-1519, 2015

11) Behme D, Weber A, Kowoll A, Berlis A, Burke TH, Weber W: Low-profile Visualized Intraluminal Support device (LVIS Jr) as a novel tool in the treatment of wide-necked intracranial aneurysms: initial experience in 32 cases. J Neurointerv Surg 7: 281-285, 2015

12) Bodily KD, Cloft HJ, Lanzino G, Fiorella DJ, White PM, Kallmes DF: Stent-assisted coiling in acutely ruptured intracranial aneurysms: a qualitative, systematic review of the literature. AJNR Am J Neuroradiol 32: 1232-1236, 2011

13) Jeong HW, Seung WB: Outcomes of stent-assisted coil embolization of wide-necked intracranial aneurysms using the solitaire ${ }^{\mathrm{TM}} \mathrm{AB}$ neurovascular remodeling device. J Cerebrovasc Endovasc Neurosurg 17: 301-312, 2015

14) Katsaridis V, Papagiannaki C, Violaris C: Embolization of acutely ruptured and unruptured widenecked cerebral aneurysms using the neuroform2 stent without pretreatment with antiplatelets: a single center experience. AJNR Am J Neuroradiol 27: 1123-1128, 2006

15) Park KW, Hwang SJ, Kwon DA, et al.; Korea Stent Thrombosis Investigators: Characteristics and predictors of drug-eluting stent thrombosis: results from the multicenter 'Korea Stent Thrombosis (KoST)' registry. Circ J 75: 1626-1632, 2011

16) Wang C, Tian Z, Liu J, et al.: Flow diverter effect of LVIS stent on cerebral aneurysm hemodynamics: a comparison with enterprise stents and the pipeline device. J Transl Med 14: 199, 2016

17) Cho SH, Jo WI, Jo YE, Yang KH, Park JC, Lee DH: Bench-top comparison of physical properties of 4 commercially-available self-expanding intracranial stents. Neurointervention 12: 31-39, 2017

18) Cai K, Ji Q, Cao M, Shen L, Xu T, Zhang Y: Association of different stenting procedures with symptomatic thromboembolic complications in stent-assisted coiling of ruptured wide-necked intracranial aneurysms. World Neurosurg 104: 824-830, 2017

19) Price MJ, Berger PB, Teirstein PS, et al.; GRAVITAS Investigators: Standard- vs high-dose clopidogrel based on platelet function testing after percutaneous 
coronary intervention: the GRAVITAS randomized trial. JAMA 305: 1097-1105, 2011

20) Stone GW, Witzenbichler B, Weisz G, et al.; ADAPTDES Investigators: Platelet reactivity and clinical outcomes after coronary artery implantation of drug-eluting stents (ADAPT-DES): a prospective multicentre registry study. Lancet 382: 614-623, 2013

21) Wagner H, Angiolillo DJ, Ten Berg JM, et al.; Higher body weight patients on clopidogrel maintenance therapy have lower active metabolite concentrations, lower levels of platelet inhibition, and higher rates of poor responders than low body weight patients. J Thromb Thrombolysis 38: 127-136, 2014

22) Bonello L, Tantry US, Marcucci R, et al.; Working Group on High On-Treatment Platelet Reactivity: Consensus and future directions on the definition of high on-treatment platelet reactivity to adenosine diphosphate. J Am Coll Cardiol 56: 919-933, 2010
23) Ferreira IA, Mocking AI, Feijge MA, et al.; Platelet inhibition by insulin is absent in type 2 diabetes mellitus. Arterioscler Thromb Vasc Biol 26: 417-422, 2006

24) Zhang J, Yang J, Chang X, Zhang C, Zhou H, Liu M: Ozagrel for acute ischemic stroke: a meta-analysis of data from randomized controlled trials. Neurol Res 34: 346-353, 2012

25) Endo H, Matsumoto Y, Kondo R, Suzuki I, Kikuchi T, Tominaga T: [Basic technique of the coil embolization and parent artery occlusion for cerebral aneurysms]. No Shinkei Geka 40: 1107-1118, 2012 (Japanese)

Address reprint requests to: Kouhei Nii, MD, PhD, Department of Neurosurgery, Fukuoka University Chikushi Hospital, 1-1-1 Zokumyoin, Chikushino, Fukuoka 818-8502, Japan.

e-mail: k.nii@cis.fukuoka-u.ac.jp 